\title{
Uma serra de forrós: sociabilidade e festas em Gameleiras - RN
}

Flávio Rodrigo Freire

Ferreira (

UNICAMP)
Após chegar à Gameleira, andando pelas estradas de barro batido da serra, ouvi o som de uma sanfona bem tocada que rapidamente atraiu minha atenção. Perguntei a Severino, Domingos de onde vinha e do que se tratava, e ele de pronto respondeu: "É da casa de Loza é nosso forró, o forró da Gameleira!".

Este artigo propõe uma reflexão sobre as festas de forró que acontecem num ambiente rural do interior do estado do Rio Grande do Norte, a Serra da Gameleira. Trata-se de um espaço social no qual grupos de diferentes origens étnicas ${ }^{1}$ mantêm um convívio marcado historicamente por relações tensas e conflituosas. Nesse espaço, o elemento que mobiliza todos os moradores que residem na Serra são as festas de forró, momento em que os grupos familiares se encontram. Diante disso, indaga-se: como é constituído o conjunto de relações sociais que acontecem na Serra em torno do forró? Como as festas acontecem? Nas festas de forró que ocorrem na Serra da Gameleira, campo empírico desta pesquisa, existe uma intensa sociabilidade festiva entre os diferentes grupos? Essas perguntas são feitas privilegiando-se a perspectiva etnográfica, pois a festa não aparece somente como um espaço de lazer e divertimento que grande parte dos moradores vivencia, mas como um lugar que oportuniza a reunião entre os grupos familiares. Nas festas, desenvolve-se um tipo de sociabilidade (McCallum 1998; Rezende 2001; Magnani 1998) dotada de uma linguagem própria que possibilita a convivência entre os grupos, além de organização típica para a realização das festas. Assim, buscamos compreender como as festas informam sobre a organização social (Woortmann 1995; Leach 1996) de um espaço disputado por grupos familiares distintos.

A partir das conversas travadas com nossos interlocutores ${ }^{2}$ e durante a observação das festas, percebemos que é através do encontro nas casas de forró, da organização interna em cada local onde as festas ocorrem, bem como dos diferentes momentos da vida diária que elas se tornam um acontecimento 
central para a vida dos moradores da Serra. Essas situações que se apresentavam em campo proporcionaram a seguinte indagação: é possível, a partir da observação das festas de forró, fazer uma leitura sobre a vida na serra, a apreensão e a definição das relações sociais?

A observação das festas de forró na Serra da Gameleira aproxima-se da seguinte idéia: "A festa não se reduz à festa" (Mériot 1999: 7). Sua ocorrência traz consigo significados diversos, fornecendo a oportunidade de colocarmos questões essenciais para pensar o universo cultural e social de determinados grupos - neste caso refletida a partir da noção de "fato social total" (Mauss 1974). É preciso tratar a festa como linguagem reveladora do mundo social e apreender o conjunto de elementos existentes que permitem comunicação entre os grupos (Amaral 1998).

Foi a partir das indicações de uma liderança local que pude chegar aos primeiros interlocutores. Utilizamos o método etnográfico, através da observação participante, na qual o olhar, o ouvir e o escrever proporcionam o encontro entre os saberes teóricos e práticos (Oliveira 1998). Com pesquisa de campo intensiva realizada de maio a agosto de 2008 e incursões até janeiro de 2009, levantamos os dados em entrevistas não-diretivas com organizadores, tocadores e forrozeiros, participantes das festas de forró na Gameleira, assim como através da produção de notas de campo.

\section{FORRÓ E SOCIABILIDADE}

Atualmente o forró tem uma dupla importância, pois está bastante presente tanto no passado quanto no cotidiano das pessoas que vivem na Gameleira. De acordo com Chianca (2006: 87), forró é festa, é dança e é música, pois "dança-se forró num forró, enquanto se escuta um forró", ou seja, o termo "forró" tem pelo menos três sentidos. Apesar de destacar sua importância, aqui não interessam os aspectos performáticos que fazem parte do dançar forró; ${ }^{3}$ o esforço estará centrado apenas no forró enquanto festa. ${ }^{4}$ De acordo com Dominique Dreyfus em $A$ Vida do Viajante (1996), existia, já em meados da década de 1920, um tipo de festa que a autora designa como forró. Assim, ela põe em evidência a importância das festas no ambiente rural. Porém, foi somente "no final da década de 1970 [que] a palavra forró adquiriu um segundo sentido [...]. O forró, que significava originalmente 'baile', passou a designar também o ritmo com que se dançava no baile" (Dreyfus 1996: 275).

As festas de forró se caracterizam como uma das poucas ocasiões propícias ao lazer na Serra da Gameleira. É preciso considerar que até alguns anos atrás era uma das únicas opções noturnas de lazer, em um lugar que só recentemente começou a dispor de energia elétrica. Por isso, as festas funcionam como um "cimento" entre os diferentes grupos de residência (Woortmann 1995) que compõem a Serra.

Os forrós da Gameleira caracterizam-se por serem atos formalizados, expressivos e portadores de uma dimensão simbólica. Além disso, as festas têm uma estrutura morfológica própria de caráter repetitivo. Caracterizam-se por sua dimensão coletiva, e por uma "configuração espacial-temporal determinada, além de portarem elementos codificados e emblemáticos, estados de transição e um significado social" (Segalen 2002: 
31) que serão demonstrados adiante, pensando as festas como "atividades [rituais] regulares" (Valeri 1979: 95, Grifos meus). Segundo este autor, as festas podem representar a sociedade em uma forma sintética e ideal, fazendo-a mais facilmente perceptível como uma totalidade. Demonstraremos a vida na Serra como uma totalidade expressa através das festas (Mauss 1974; Durkheim 1978).

Nesse sentido, as festas de forró são práticas sociais que revelam uma ordem social vivenciada através de certo tipo de sociabilidade. Realizando uma arqueologia do uso dos termos socialidade e sociabilidade na obra de G. Simmel, Marilyn Strathern mostra que "Sociabilidade tem a ver com a constituição social e moral de 'relatedness' (o estado de estar relacionado)" (Strathern apud McCallum 1998: 1). O estudo de Vianna (1988: 69) aproxima-se de uma utilização dos termos quando coloca que "não existe um objetivo [para sua reunião], mas estão reunidos [também] pela satisfação de estarem juntos".

Desse modo, apresentaremos as festas de forró como momentos em que se desenvolve uma sociabilidade festiva, quando observamos uma circulação de todos os moradores da Serra (McCallum 1998). As festas funcionam no sentido de "Fabricar uma sociabilidade que extrapole os limites de uma série de relações sociais" (McCallum 1998: 11). Através delas, loci em que todos os grupos se envolvem, acabam por se reforçar certos tipos de relação (Rezende 2001: 1). Nesse sentido, podemos falar em uma sociabilidade festiva intrinsecamente ligada à vida dos grupos.

\section{A GAMELEIRA E OS ENCONTROS FESTIVOS}

A Serra é formada por três grupos residenciais: Chaves Belas, Salgadinho (ou Gameleiras de Cima) e Gameleiras de Baixo. Esta divisão é afirmada pelos próprios moradores da serra. A referência é precisa quando alguém aponta de onde uma pessoa é: "Ah, é [d]aqui da Serra mesmo! [d]Ali de Chaves Belas" ou "D'ali de Salgadinho". As pessoas frequentemente se deslocam e circulam entre estas três pequenas localidades. Todos se conhecem e se relacionam, sempre reconhecendo de onde cada um é (se Chaves Belas, Gameleira de Cima ou de Baixo), uma vez que cada uma dessas áreas dispõe de origens familiares distintas. A partir dessa organização interna, todos se reconhecem como sendo "da serra". As diferenças funcionam como marcadores de um conhecimento sobre as redes de parentesco que dão vigor às práticas de sociabilidade e que formam um tipo de identidade local (Magnani 1998), no qual as pessoas estão agrupadas num todo maior, que é a Serra da Gameleira.

A Serra da Gameleira é um espaço social circunscrito que integra grupos sociais familiares através de certo modo de convivência e interação. Os lugares de sociabilidade na Gameleira são: o orelhão, as igrejas católica e evangélica, as escolas, as associações comunitárias, os bares, os açudes, os roçados, o olho d'água e, por último e não menos importante, as festas de forrós. Quando se fala em formas de diversão, momentos de encontros entre as pessoas ou de lazer na Serra, todos, independentemente de sexo ou idade, fazem referência às festas de forró. Os mais velhos logo associam as festas à "tradição" local, devido ao tempo memorial em que elas ocorrem. 
Assim, a serra não é um espaço vazio ou inóspito, mas um local repleto de históricas relações sociais que possuem regras internas de convivência. As pessoas frequentam esses locais, principalmente as festas de forró, não de forma aleatória, mas porque a convivência é tida por eles como "interessante". São espaços de lazer e diversão nos quais encontros entre os moradores acontecem. Os lugares festivos, portanto, propiciam momentos de sociabilidade.

Quem é da Gameleira é da Serra e, por isso, conhece as regras do local. As festas formam uma "rede de relações que combina laços de parentesco, vizinhança, procedência etc." (Magnani 1998: 115), vividos intensamente pelos moradores da Serra. Os trajetos são traçados entre os lugares festivos, ligando pontos que aqui são denominados de casas de forró. Como todas as festas que acontecem na Serra estão "articuladas", pensa-se também em trajetos festivos, retomando uma metodologia descritiva de Magnani (1998), uma vez que as festas ocorrem alternadamente nos diferentes locais.

\section{UMA SERRA DE FORRÓS}

Articulados por uma rede de relações sociais, favorecendo a sociabilidade e a integração, os lugares festivos formam um círculo e acontecem durante o ano inteiro. É inconcebível pensar a Serra sem a existência do forró. Quando perguntados sobre festividades, grande parte dos moradores da Gameleira queria falar somente sobre forró.

$\mathrm{Na}$ Serra da Gameleira não existe apenas uma festa de forró. Na verdade, são cinco centros festivos, nos diferentes locais, que proporcionam convívio entre todos da Serra - quadro este que inspirou a escolha do título “Os Forrós nas Gameleiras" para o presente estudo. O forró acontece alternadamente nesses locais, favorecendo a integração e a união entre as pessoas. No entanto, existe uma "tradição" festiva mais ligada à Gameleira de Baixo que remonta a rabequeiros e sanfoneiros antigos. Como veremos muitos sanfoneiros continuam fazendo musica, dando continuidade a essa tradição.

A figura a seguir mostra a localização das casas de forró "oficiais" - lugares festivos reconhecidos localmente como forrós e que são também moradia. Todavia, existem festas de forró em locais "não-oficiais", quando qualquer pessoa faz um forró em sua residência motivado por alguma data festiva, como um aniversário, um casamento, para comemorar o dia de um santo, entre outras ocasiões. Nesta figura, localizam-se os lugares festivos que existem, enfatizando a dinâmica das relações sociais, fundamentais para compreender a sociabilidade, a cooperação e a união que ocorrem entre os grupos familiares por meio das festas na Serra da Gameleira. 


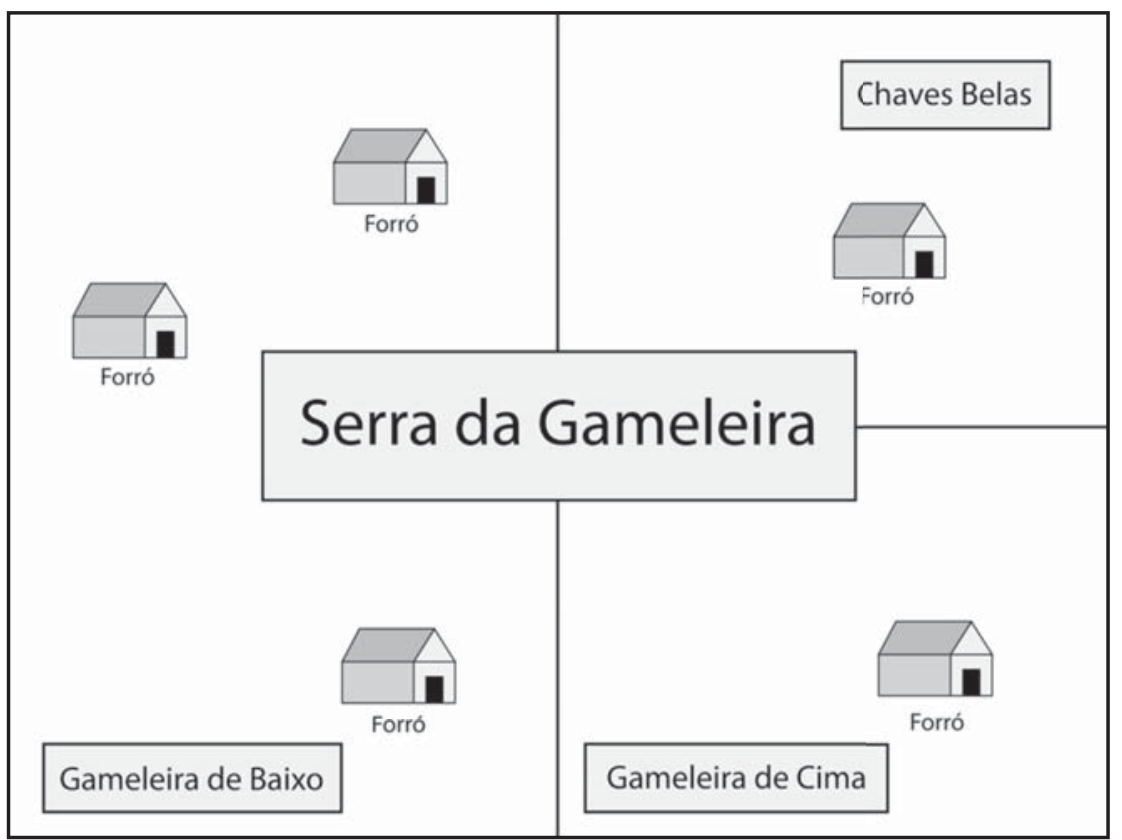

Figura 1 - Os forrós da Serra.

Fonte: Elaborado pelo autor.

O quadro seguinte apresenta as festas observadas. Foi elaborado a partir do acompanhamento prévio e posterior das festas de forró, ocorridas de junho de 2008 a janeiro de 2009, totalizando 15 festas. Percebe-se neste quadro que entre os meses de agosto, setembro e outubro houve apenas uma festa de forró na Serra, acontecida no dia da padroeira, ao contrário dos meses de junho e julho, quando houve 1/3 do total das festas. O quadro oferece informações a respeito das datas de acontecimento, sobre as casas de forró (ocasionalmente com as suas respectivas motivações) e sobre os locais na Serra (e fora dela) em que as festas foram realizadas. 


\begin{tabular}{|c|c|c|c|}
\hline & Data & Motivação + Casa de Forró & Local na serra \\
\hline 1 & 14 de junho de 2008 & Forró de São João em Neném & Gameleira de Cima \\
\hline 2 & 21 de junho de 2008 & Forró de São João em Loza & Gameleira de Baixo \\
\hline 3 & 27 de junho de 2008 & Forró de São João em Piaba & Gameleira de Baixo \\
\hline 4 & 28 de junho de 2008 & Forró de São Pedro na residência de "Lú" & Chaves Belas \\
\hline 5 & 19 de julho de 2008 & Forró de Sant'Anna em Luiz Besouro & Gameleira de Baixo \\
\hline 6 & 16 de agosto de 2008 & $\begin{array}{l}\text { Forró da festa da padroeira em Loza (Único } \\
\text { forró do mês de agosto) }\end{array}$ & Gameleira de Baixo \\
\hline 7 & 07 de setembro de 2008 & $\begin{array}{l}\text { Forró realizado fora da Gameleira (Os } \\
\text { tocadores saem da Serra, e se apresentam } \\
\text { em uma cidade vizinha) }\end{array}$ & $\begin{array}{l}\text { Município de Cerro-Corá } \\
\text { (RN) }\end{array}$ \\
\hline 8 & 08 de novembro de 2008 & Forró em Neguinho Israel & Chaves Belas \\
\hline 9 & 15 de novembro de $2008^{*}$ & Forró em Piaba & Gameleira de Baixo \\
\hline 10 & 29 de novembro de 2008 & Forró em Loza & Gameleira de Baixo \\
\hline 11 & 05 de dezembro de 2008 & Forró em Neném & Gameleira de Cima \\
\hline 12 & 13 de dezembro de 2008 & Forró em Luis Besouro & Gameleira de Baixo \\
\hline 13 & 31 de dezembro de 2008 & Forró de ano novo em Piaba & Gameleira de Baixo \\
\hline 14 & 17 de janeiro de 2009 & Forró em Neném & Gameleira de Cima \\
\hline 15 & 24 de janeiro de 2009 & Forró em Piaba (com Loza tocando) & Gameleira de Baixo \\
\hline
\end{tabular}

* Esse forró foi adiado no dia de sua ocorrência, devido a um falecimento na serra. Quadro 1 - Ocorrências das festas de forró. Fonte: Elaborado pelo autor 
O quadro anterior mostra que as festas podem ser pensadas como parte integrante de uma rede festiva fundamental para que os forrós aconteçam. Seus membros incluem os organizadores e os donos das casas de forró, os animadores, os tocadores e os forrozeiros. Identificam-se os lugares festivos a partir da etnografia. A todos é permitido participar das festas, sem restrições. Frequentar esses espaços é mover-se numa rede social que possibilita manter contatos diretos, muito valorizados, com vários tipos locais.

\section{OS DONOS DOS FORRÓS}

A descrição dos lugares festivos inicia-se através da organização interna das festas de forró, que funciona sistematicamente de acordo com os locais destinados para a realização das celebrações. Percorri os cinco centros festivos da Serra, começando por Gameleira de Baixo, passando pela Gameleira de Cima e chegando a Chaves Belas. Em cada um desses locais, obtive a colaboração de interlocutores envolvidos com a organização dos eventos, os chamados "donos do forró". Nas conversas iniciais, supus que os donos dos espaços eram os únicos a promover as festas, e só depois é que compreendi como realmente se configuram as festas de forró.

A organização específica de cada festa, nas três localidades que compõem a Serra, segue um padrão preestabelecido. O local, o horário, quem toca, o dia da festa, o valor da entrada e se mulher irá pagar são pontos decisivos em termos de participação, uma vez que os eventos acontecem em quase todos os finais de semana, dependendo do período anual, aumentando as possibilidades de escolha dos moradores. As formas de sociabilidade estão estreitamente relacionadas à realização das festas de forró e constituem elemento central do evento, devendo ser compreendidas a partir da natureza da celebração. Uma festa com pouca participação ou poucas pessoas não é considerada um acontecimento bom, e por isso a organização é tão importante. Quando se fala em "casa cheia", significa que o limite ou a quantidade de participantes do forró excedeu sua capacidade, o que é uma constante - segundo os responsáveis pela organização, nunca houve festa com pouca gente e isto é algo no mínimo inconcebível para os que vivem as festas de forró.

No entanto, esse padrão começa a variar a partir do momento em que saímos do âmbito geral da organização e focamos as características peculiares dos organizadores, ou seja, dos donos dos forrós. Nem sempre os organizadores dos eventos são os proprietários do espaço físico destinado à realização da festa, mas, mesmo assim, ainda são considerados os donos da festa, como foi observado na festa da padroeira Nossa Senhora da Guia. Neste caso, a organizadora é uma liderança católica na Serra, filha do principal líder religioso que construiu a capela da Gameleira ao lado da sua casa, seu Zé Menino.

Quem são essas pessoas "donas" dos forrós? Escolhi apenas os proprietários dos espaços físicos, devido à facilidade de localizá-los e entrevistá-los, assim como a regularidade com que realizam as festas. Através das entrevistas, descreverei quem são os donos dos espaços físicos onde as festas acontecem.

Não é qualquer pessoa que pode ter um forró, mas apenas aqueles que são considerados os seus "guardiões". O dono de um forró é legitimado pela relação que mantém ao longo da vida com as festas. Pode ser 
o filho, o sobrinho, o genro de um ex-forrozeiro ou mesmo de um ex-tocador, ou ter algum grau de parentesco com ele. Na Gameleira de Baixo são três os donos de espaços onde as festas acontecem.

Começarei por José Ronildo Domingos, ou simplesmente "Piaba", como é mais conhecido. Piaba é casado com sua prima, filha de Severino Domingos. Tem legitimidade para organizar as festas por vir de uma família que tem história com os forrós. Os primeiros eventos organizados por ele na Serra aconteceram na escola do distrito e com a autorização da prefeitura. Quando a prefeitura deixou de ceder o espaço para os acontecimentos festivos, José Ronildo decidiu construir um espaço na Gameleira para realizar os seus forrós. Ele relembra: “Resolvi fazer meus forrós em casa mesmo. Desde 1996 que eu tenho minha casa própria de forró. É conhecida demais, [por] todo canto que [você] andar por aqui o povo sabe do forró de Piaba". Esse forró fica localizado no ponto mais baixo da Gameleira. Seguindo seu caminho, chega-se ao campo de futebol, ao pequeno açude, à capela e, seguindo mais adiante, em Chaves Belas.

O dono do forró enfatiza a importância das festas no cenário local, dizendo que na Serra "para forró, todo tempo é tempo". Apesar dessa constância, ele ressalta que "o mês de junho não tem igual, parece que é mais animado por ser o mês de São João. Já os meses de janeiro, fevereiro e março são fracos de forró, quase não tem, pois todos estão voltados para a agricultura". Essa afirmação nos remete a Marcel Mauss (2003) e a sua observação das variações sazonais nas sociedades esquimós, onde cada atividade coletiva acontecia em um tempo determinado.

De acordo com Piaba, a organização dos eventos é toda realizada por ele. Somente para divulgação é que conta com o auxílio de outra pessoa, chamada de animador, responsável por colocar os cartazes e avisar nas rádios. Ele explica:

Eu é que tomo conta de tudo, faço serviço de bar e aqui mesmo consigo algum primo pra ficar na portaria. Meu forró aqui é sempre lotado, tendo forró em Piaba, todo mundo vem. Principalmente o pessoal aqui da comunidade, de Chaves Belas ou de Salgadinho. Aqui é o povo de toda idade, é velho, é novo, todo mundo dança e brinca nos forrós. Depois que fecho com a banda, o forró tá garantido. As bandas também são aqui da região, já trouxe bandinha de Santa Cruz, Lajes Pintadas. Faz uma portariazinha cobrando R\$ 5, quando a banda é melhorzinha, aí a gente cobra R\$2 de mulher (José Ronildo Domingos, “Piaba”, 35 anos, Gameleira de Baixo, novembro de 2008).

Segundo Piaba, quando passa um mês ou dois sem organizar nenhuma festa, as pessoas já ficam cobrando: “'mas, Piaba, nunca mais teve um forró?!' Depois vem o pessoal das bandinhas e sugere: ‘Ei, Piaba, vamos ajeitar um forró, mais nunca fizesse'". Essa festa em especial ocorre com uma maior regularidade. Como visto na declaração acima, Piaba preza muito a concorrência e se esforça para não ficar atrás dos outros na organização das festas.

Outro dono de forró na Gameleira de Baixo é Francisco Félix dos Santos, o Loza do Acordeon, que abriu sua casa juntamente com a sua esposa, Chiquinha, e seu enteado, Mecías. Loza, desde criança, tem um profundo envolvimento com os forrós. Ele relata que seu espaço não é muito antigo e antes só tocava quando os donos da festa o convidavam. Resolveu fundar o forró quando seu enteado começou a cantar profissionalmente no ano de 2004. 
O espaço em que Loza realiza suas festas é bastante amplo. Tem uma estrutura maior do que a de Piaba, pois dispõe de palco, cobertura parcial, além de ser murado. O forró de Loza segue a lógica das festas da Serra, porém tem suas regras próprias para poder concorrer com os demais, como a questão do preço da entrada: “Aqui sempre a gente arruma uma portariazinha de $R \$ 5$, quando não tem 5 , entra com $3,2, R \$ 1,50$. Não tem isso, não! E graças a Deus nunca tenho prejuízo, já fiz forró aqui e arrumei de 700 a 800 contos".

Por também ser tocador, Loza tem uma percepção diferenciada dos demais donos de casas de forró, quase sempre se sentindo desprestigiado na comunidade pelos demais proprietários. Durante a entrevista, Loza falou sobre uma festa que iria promover, relembrou como foi a primeira que organizou e ainda desabafou sobre o tempo em que não tinha seu próprio espaço para realizar festas:

Aqui, nesta casa, o primeiro forró que eu fiz foi em 2004, era aniversário de Mecías, deu muita gente e foi muito bem-visto, graças a Deus, o pessoal prestigiou bastante. Foi a primeira vez que eu toquei sem ser nas casas dos outros, toquei na minha casa de forró. A partir desse dia, eu posso me orgulhar de tá fazendo o meu forró. Antes tocava em Luís Besouro, em Neném, em Piaba, aqui em Chaves Belas, mas o pessoal daqui mesmo não valoriza muito, sabe? Então é melhor ter minha casa de forró porque lá quem manda sou eu. Agora que pude começar a fazer um bar melhorzinho aqui no salão. Acontece o seguinte, por eles a gente não toca aqui, porque não valoriza e prefere chamar gente de fora (Francisco Félix dos Santos, “Loza”, 57 anos - Gameleira de Baixo, novembro de 2008).

O último dono de forró na Gameleira de Baixo é Luís Bezerra da Silva, mais conhecido como "Luís Besouro", da família dos "Besouros" de Chaves Belas. Ele tem 54 anos e se dedica à atividade de forrozeiro e à agricultura. Além disso, tem um pequeno comércio no qual vende um pouco de tudo. Seu forró está localizado em um ponto central da Serra, no caminho que segue para a Gameleira de Cima. Luís Besouro também tem adotado uma perspectiva de competição com os demais donos de forrós, sendo, no entanto, mais rígido nas suas posições. Ele define, sempre enfatizando, o que é certo a partir da sua posição de dono de forró - desde reivindicar anterioridade do seu forró em relação aos demais até a questão dos preços das entradas na festa.

O certo mesmo era que o meu forró, aqui na Gameleira, fosse o mais antigo, porque eu já trago ele lá de Chaves Belas. Minha família é toda nascida e criada aqui na Serra, só que ali em Chaves Belas. Vim pra cá já tem uns dez anos e sempre organizando forró, não tem igual ao meu. Quando organizava os forrós lá, todo mundo daqui descia pra lá, agora o povo de lá que vem pr'aqui [risos]. Você precisa vir em um forró que eu fizer aqui, viu? E não vai pagar entrada, não! Aqui no meu forró só quem paga pra entrar são os homens mesmo, é R\$5, porque o certo mesmo é mulher não pagar. Nunca vi fazer um forró e mulher pagar ${ }^{5}$. Por aqui tem gente que cobra, viu? Mas eu nunca fiz, e olhe que faz tempo que faço forró aqui, vejo as mulheres irem e ficarem fora. Aí também não aparece homem no salão porque não tem com quem dançar, depois reclamam que o forró foi fraco, não sabe fazer, né?! (Luís Bezerra da Silva, "Luís Besouro", 54 anos - Gameleira de Baixo, novembro de 2008).

O depoimento de Luis Besouro revela muito sobre as disputas entre os donos dos forrós. É uma competição interna para aglutinar o maior número de pessoas nas suas festas. Diante dessa concorrência, as festas são pensadas de acordo com os outros donos e isto faz com que Luís Besouro fixe um preço único, mas apenas para os homens. Como diz Luís, destacando a importância das festas e reforçando a nossa percepção sobre o papel 
de sociabilidade dos forrós, "o povo aqui gosta muito de estar nos forrós, porque senta nas mesas, conversa, bebe, dança, encontra com os primos. Eu vejo muita gente que só se fala quando se encontra nos forrós".

No forró de Luís Besouro quem tem a preferência para tocar é Loza do Acordeon e Mecías Show. De acordo com ele, é vantagem chamá-los para tocar porque, como são da Serra, não teriam problema em não receber o valor integral do pagamento acordado se a festa for "fraca". O pagamento do tocador é feito após a realização do forró, mas existe um acerto anterior de um valor médio estipulado. A maior parte do valor arrecadado na portaria com a cobrança das senhas de entrada serve para pagar o tocador. A outra forma de arrecadação de dinheiro é através do bar, com a venda de bebidas - lucro este inteiramente do dono da casa de forró.

Esse proprietário confessou que não tinha problema com ninguém do local, mas que já havia se desentendido com uma pessoa por ser organizador de forró. Ser dono de forró é ficar muito exposto e conhecido na Serra, por isso cada um tem a sua visão a respeito das pessoas que frequentam o forró. No final de uma entrevista, Luís Besouro tentou amenizar o que havia falado outrora sobre a competitividade entre eles - os donos. Ele comenta: "Ninguém pode atrapalhar o forró do outro, tem que fazer em dias diferentes, para não dar problema, sabe? Porque ficar com rivalidade não dá muito certo".

É importante que os eventos organizados não coincidam, pois, além de ocasionarem concorrência nas festas, geram também um desconforto entre os donos dos forrós. Segundo Luís, o ideal é que as datas não sejam muito próximas - como um forró na quinta e outro no sábado - uma vez que é preciso haver um tempo mínimo de uma semana, pois $\mathrm{R} \$ 5$ - o custo médio de entrada para as festas - é um valor que faz falta no orçamento das famílias.

De fato, em meio às disputas, existe um comum acordo entre os donos dos forrós. A fala seguinte de José Ronildo, “O Piaba", ilustra bem esse tratado informal que está implícito: “No dia que eu marco de fazer, Loza não faz; quando Loza faz, eu não faço. Quando ele marca um forró de hoje a 15 dias, eu só marco de hoje a um mês, 15 dias depois do dele. É tudo combinado".

Em Chaves Belas há apenas um dono de forró responsável pela realização das festas. Chama-se Israel Souza, mais conhecido como "Neguinho Israel". Ele tem 41 anos e também vive da agricultura. Sua iniciação nas festas de forró teve como causa a perda na animação local do mestre do Boi Reis, seu Severino Mãozinha, tio de Loza. Outro motivo, segundo Neguinho Israel, foi porque

[...] na Serra toda já tinha forró, menos aqui. O pessoal daqui começou a reclamar que não tinha uma festa aqui. Então fiz meu primeiro forró e a lotação foi grande. Rapaz, o povo todo aqui da Serra subiu pra cá! E foi assim que eu comecei.

Ele legitima seu forró em função de uma motivação dos próprios moradores, para não ficarem atrás na organização e na concorrência em relação às festas.

Por fim, chegamos a Gameleira de Cima, que também conta apenas com uma casa de forró cujo dono, chamado Vicente Lopes Pereira, é mais conhecido como “Neném”. Ele é o vice-presidente da Associação 
Comunitária da Gameleira de Cima, tem 49 anos e é filho de Arnaldo Lopes (família representante da Gameleira de Cima). Localmente, é reconhecido como um líder político na defesa dos interesses dos moradores da Gameleira de Cima. Dono da única casa de forró dali, ele a criou há aproximadamente dez anos, mas antes um primo seu já realizava festas de forró no local. Sua casa fica em um ponto estratégico central e de passagem pela comunidade e consta de várias residências adjacentes. Sua ideia era poder realizar festas também na Gameleira de Cima, visto que, segundo ele mesmo disse, "em Baixo sempre teve as festas dos negros". Neném também é responsável pela organização dos festejos juninos em Gameleira de Cima, evento que reúne pessoas de toda a Serra. Suas filhas organizam, convocam os jovens e coordenam os ensaios da única quadrilha junina da Gameleira que se apresenta fora dos limites da Serra.

Estes são os cinco donos do espaço físico - ou casas de forró - e também organizadores das festas na Serra da Gameleira. O Quadro seguinte relaciona as cinco casas existentes na Serra, com seus respectivos donos e a sua localização.

\begin{tabular}{|c|c|c|c|}
\hline & Casa de Forró (como é conhecida) & Dono (responsável) & Local na Serra \\
\hline 1 & Forró de Piaba & José Ronildo Domingos & Gameleira de Baixo \\
\hline 2 & Forró de Loza & José Félix dos Santos & Gameleira de Baixo \\
\hline 3 & Forró de Luiz Besouro & Luiz Bezerra da Silva & Gameleira de Baixo \\
\hline 4 & Forró de Neném & Vicente Lopes Pereira & Gameleira de Cima \\
\hline 5 & Forró de Neguinho Israel & Israel Souza & Chaves Belas \\
\hline
\end{tabular}

Quadro 2 - As casas de forró da Serra. Fonte: Elaborado pelo autor

Conforme o quadro exposto, são três casas na Gameleira de Baixo, uma em Chaves Belas e outra na Gameleira de Cima. Estas são as casas de forró consideradas fixas, porém, dependendo da motivação, existem casos de outros moradores que organizam sua própria festa de forró em suas residências. Na relação existente entre as pessoas que frequentam esses centros festivos, os chamados forrozeiros, a festa funciona como elemento integrador, "cimento" social, que une e possibilita o encontro entre as pessoas da Serra da Gameleira. 


\section{OS FORROZEIROS}

São as pessoas que frequentam com regularidade as festas de forró na Serra da Gameleira. É uma categoria fluida, pois não existe uma característica precisa que diferencie ou determine quem são os forrozeiros. As pessoas entrevistadas na Serra consideram-se participantes ativas das festas. O forrozeiro ouve e dança forró, espontaneamente, o ano todo. Seu repertório não é limitado, apenas dirigido a um gosto musical comum sancionado ao longo do tempo pelos moradores da Serra, além disso, os forrozeiros não têm o mínimo interesse em escutar ou dançar outras músicas.

É interessante notar que vários forrozeiros locais extrapolam os limites de ocorrência do forró apenas no espaço da Serra. Em conversa com alguns familiares, pude perceber a importância de sair para os forrós nos arredores: "O bom é ir também a festas em outras comunidades, pois a pessoa fica mais 'desenrolada'" (o termo se aplica a certa desenvoltura em sair dos limites da Serra). Este depoimento frisa a relevância que as festas adquiriram na Serra, ser forrozeiro é poder acompanhar o forró nos circuitos locais e até mesmo em circuito mais restrito, é a necessidade de viver "uma diferenciação contínua e sistemática dos iguais" (DaMatta 1986: 149), é diferenciar-se em relação às pessoas de dentro e de fora da Serra.

\section{O FORRÓ “DENTRO" DAS CASAS}

Como vimos, aqueles que organizam as festas são também os donos dos lugares conhecidos como casas de forró. Os espaços físicos onde as festas de forró acontecem são lugares fixos, localizados nos próprios domicílios desses donos. Roberto DaMatta (1981), em seu estudo sobre o carnaval brasileiro, coloca "o espaço familiar das casas como espaço de intimidade e as ruas como espaço público" (DaMatta 1981: 81). Na Gameleira, esta dicotomia é relativa, pois o espaço familiar da casa é íntimo, mas também é aberto ao público. Essa realidade nos provoca o seguinte questionamento: qual o significado de as festas de forró acontecerem dentro das casas?

O fato de a casa ser um espaço ao mesmo tempo íntimo e público é de extrema relevância, pois a intimidade entre os donos e as pessoas que frequentam os forrós é uma dimensão vivida também através dos laços familiares. Os mais próximos, principalmente parentes, circulam no espaço da casa residência, não ficando restritos ao lugar reservado para dançar. Talvez a popularidade que as festas de forró têm esteja relacionada à sensação de se estar em casa, mesmo em um ambiente público, o que os moradores da Serra experimentam nesses salões. As festas acontecem dentro do domicílio porque isto facilita e serve como ponto de apoio para a realização do evento.

As casas de forró demarcam a permanência dos pontos que compõem os lugares festivos da serra. Tais casas, pela frequência e pelo tempo em que realizam as festas, tornaram-se reconhecidas como espaços festivos. Desenvolverei a ideia de que alguns desses espaços, neste caso, o das casas de forró, seriam particularmente propícios à integração e à sociabilidade (Rezende 2001). As casas de forró, enquanto pontos fixos, são referências 
de localização na Serra, pois são facilmente identificadas até por quem não é do local e, como observaremos adiante, as casas têm características próprias que as tornam diferentes das demais.

Todas as casas são espaços construídos pelos próprios donos do forró, como indica o depoimento de Israel em Chaves Belas, ao narrar a maneira simples com que ergueu sua casa: “Cimentei e cerquei o salão e tá aí esse espaço que você tá vendo no terreiro da minha casa. É onde faço as festas". Sem dúvida existe uma relação tênue entre os espaços que fazem parte da "casa", pois considero se tratar de uma categoria genérica que caracteriza a festa. As casas devem dispor de um amplo espaço para que haja circulação de pessoas. As menores casas são a de Luís Besouro e a de Neném, respectivamente localizadas na Gameleira de Baixo e na de Cima. As demais possuem espaço interno relativamente equivalente.

Nas casas de forró também ocorre uma divisão dos papéis sociais. Em pesquisa realizada em uma comunidade rural do estado do Rio Grande do Norte, Albano (2008) mostra que a casa é um espaço social, no qual a presença feminina é muito marcante justamente por ter essa dimensão do privado. Contudo, nas casas de forró da Gameleira, só os homens aparecem. Identificou-se, durante a pesquisa, somente uma mulher que realiza forró, mas apenas ocasionalmente. Não existem mulheres donas de uma casa fixa porque somente os homens podem promover essas atividades ritualizadas (Segalen 2002).

As mulheres que participam da organização do forró são responsáveis pela venda das senhas na portaria e também pelo preparo das comidas da festa, os tira-gostos. O bar é serviço dos homens. Apesar de os homens serem reconhecidos e aparecerem como os donos das festas, em meio à organização sempre existe a presença de uma mulher, como é o caso de dona Chiquinha, esposa de Loza. Este fator é interessante para aprendermos sobre o funcionamento interno dessas "casas" como lugares de relações sociais (em seu sentido micro).

Novamente é interessante perceber que o forró, enquanto uma manifestação amplamente coletiva, toma forma partindo de uma dupla dimensão: privada e particular, que é justamente o espaço da casa (DaMatta 1981). É importante questionar ainda qual o conceito de domicílio (casa) que tinham quando iniciaram a prática das festas. Será que a casa era correspondente a um espaço apenas de convivência privada ou eram espaços de vivência comum, através dos estreitos laços de parentesco que estão muito presentes nos locais?

No forró de Seu Zé Menino, o que predomina é a fé católica, uma vez que a capela da comunidade foi construída por ele ao lado da sua casa. Mesmo assim, seus familiares se envolvem com as festas organizando o forró da padroeira em outro local que não próximo à igreja. De acordo com Zé Menino, na Serra da Gameleira as festas sempre eram realizadas num local que também servia como domicílio: "tinha casa aqui que os negros se juntavam a noite toda... dançando forró". Esta referência é sobre casas antigas, mas nos oferece pistas para a compreensão do uso do termo e a sua lógica de utilização atual. A "casa" persiste, mas com um aspecto de (semi) profissionalização.

Os donos das casas têm, necessariamente, de oferecer bebidas, como cerveja e cachaça. Elas são vendidas pelo dono do forró. Geralmente, a casa é do dono do forró, ou organizador, aquele que fica responsável por toda a estrutura necessária para receber uma festa. Esse espaço festivo pode ser considerado um elemento 
fundamental da ocorrência do forró, pois está intimamente relacionado à sua origem local. Tais casas são pontos centrais que compõem os trajetos aqui chamados de festivos para serem articulados ao conceito de lugar festivo. A ideia de trajeto neste texto está mais relacionada à sua evidência empírica e à prática formulada por Magnani (1998), explicitada a seguir.

\section{TRAJETOS FESTIVOS ${ }^{6}$}

Os lugares festivos estão interligados através de um determinado trajeto que possibilita a circulação de pessoas a todo momento, assim como a comunicação e a partilha da linguagem da festa nos diferentes lugares. Esse movimento é o percurso realizado pela pessoa para ir à festa. Por exemplo, se o acontecimento festivo ocorrer em Gameleira de Baixo, as pessoas que moram no local têm facilidade para chegar ao espaço destinado ao forró. Já as pessoas que moram em Chaves Belas e em Gameleira de Cima precisam se deslocar e percorrer certo caminho, aqui nomeado de trajeto festivo. $O$ trajeto aplica-se a fluxos num espaço mais abrangente da Serra, ou seja, entre uma e outra casa de forró. Ele é festivo porque o seu percurso também faz parte da festa.

Durante a pesquisa, tive a oportunidade de percorrer esse caminho. Para observar um forró, desloqueime da Gameleira de Baixo, onde estava hospedado, até Chaves Belas, local da festa. O trajeto foi realizado em cima da carroceria de uma caminhonete que estava lotada de forrozeiros, todos em clima de festa, cantando as canções mais lembradas no momento. O sentimento externado naquele percurso de deslocamento de uma localidade para outra era de total euforia, êxtase e expectativa de como a festa seria naquele dia. A figura a seguir demonstra o percurso. 


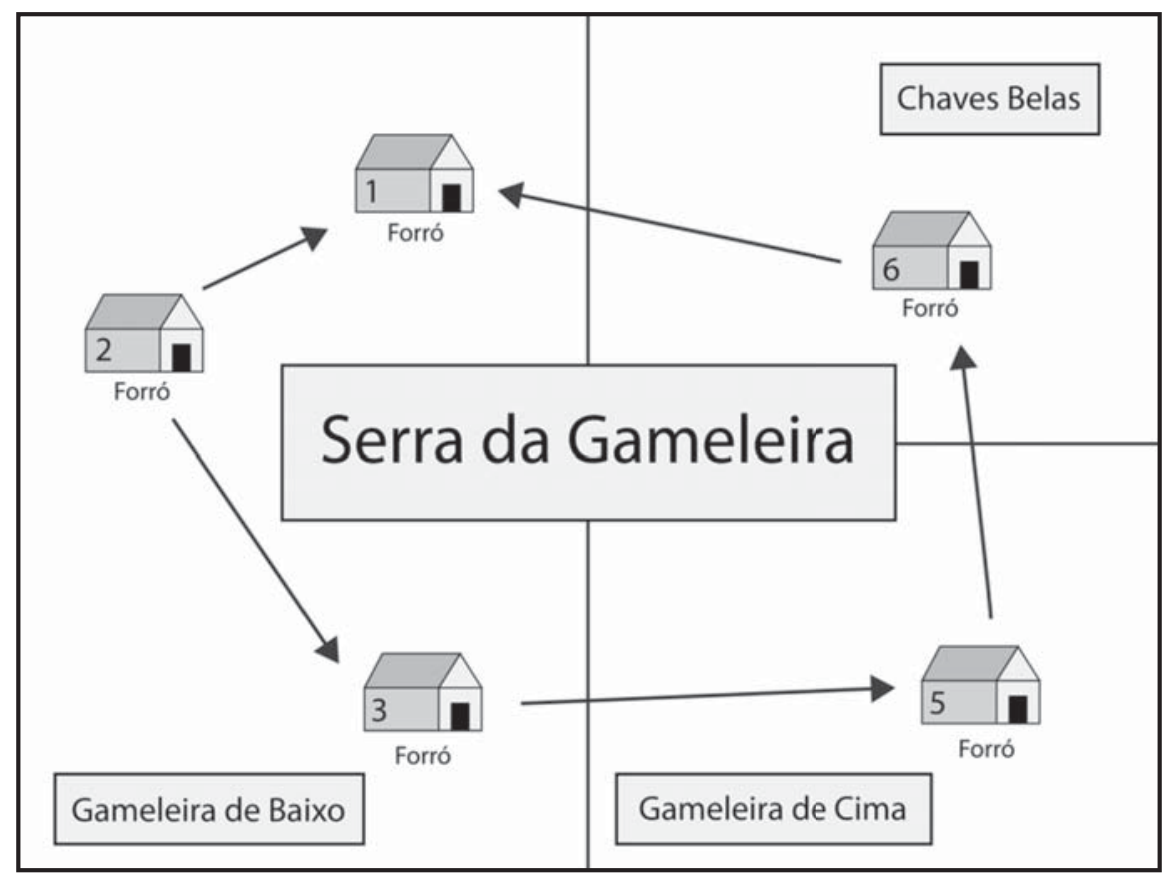

Figura 2 - Trajetos festivos.

Fonte: Elaborado pelo autor.

Podemos observar nesta figura que as três localidades estão interligadas em um trajeto que é circular. Pode-se ir da Gameleira de Baixo a Chaves Belas por dois caminhos distintos, que facilitam o acesso aos lugares de festas. Além disso, a imagem revela-nos como as moradias da Serra estão distribuídas e organizadas espacialmente.

A numeração das casas define quem são os donos das casas: (1) Forró de Piaba; (2) Forró de Loza; (3) Forró de Luís Besouro; (4) Forró de Neném; e (5) Forró de Neguinho Israel. A circulação entre esses espaços é frequente e o trajeto se realiza semanalmente, dependendo do período do ano. As casas que integram o percurso exposto são locais fixos. No entanto, também podem ocorrer eventos que não sejam necessariamente nesses ambientes.

Cartazes fixados em locais de ampla circulação divulgavam as festas da Serra no mês de junho. Das cinco casas que compõem o trajeto anteriormente descrito, duas das festas aconteceram nas casas, respectivamente, de número dois e de número quatro. Um dos cartazes aponta para uma festa realizada em Chaves Belas, mas em uma casa que não é fixa. Isto se dá recorrentemente devido ao mês junino. Quatro festas ocorreram no decorrer de junho, divulgadas também em cartazes fixados nos locais de circulação. Um deles convidava os 
forrozeiros para uma festa na Gameleira de Cima (ou Salgadinho), a ser realizada na casa de forró de "neném", chamada oficialmente de "espaço do vaqueiro". O outro, com a animação de "Neguinho", é o forró em Chaves Belas na "residência de Lu". Um terceiro convida para uma festa no espaço casa-show, ou melhor, na casa de forró de Loza do acordeon, um tocador antigo que permanece fazendo discípulos no forró, como o seu enteado Mecías. As festas de forró em seus trajetos circulam entre Gameleira de Baixo, passando por Chaves Belas e pela Gameleira de Baixo, depois se repete sem necessariamente seguir essa sequência. $O$ importante é que aconteçam por toda a Serra da Gameleira.

\section{CONCLUSÃO}

As festas de forró, que aqui são consideradas enquanto atividades ritualizadas (Segalen 2002; Valeri 1979), exprimem uma linguagem social específica (Leach 1996), visto que seguem um padrão estabelecido: apesar da aparência espontânea, eles revelam traços organizados e programados, assim como fases recorrentes.

A rede de relações sociais, construída a partir dos forrós, caracteriza o que chamamos de uma sociabilidade festiva, presente entre os grupos familiares da Serra da Gameleira. O forró-festa é o elemento de associação e integração de todos é através dele que as famílias se re-conhecem e se encontram, as pessoas circulam e se comunicam. Como foi demonstrado é um evento chave para leitura da vida social, que agrega valores fundamentais de uma cultura percebida como tradicional. Lanna (1999: 193) adverte que, no interior, o forró pode ser visto como um ritmo de união entre as pessoas. Complementaria a afirmação do autor no sentido de que não é apenas o ritmo, isoladamente, que causa união, mas a festa conhecida como forró.

Diante do exposto, pudemos perceber de que maneira se articulam os lugares festivos de ocorrência dos forrós na Serra da Gameleira. Entendemos que a organização social se firma num eixo que envolve fatores importantes - como a realização das festas, os trajetos festivos e as casas de forró - além dos personagens fundamentais para a organização e o sucesso desse circuito - donos dos forrós e forrozeiros - a fim de atrair o público e efetivar uma sociabilidade festiva entre os membros da comunidade local. Esses elementos são criadores de um quadro social que possibilita e induz os agentes nele envolvidos a conceberem e a participarem de um jogo vivencial cujo tema é a expressão de valores compartilhados por grupos que convivem historicamente com essa festa. Finalmente, é uma divertida forma de lazer coletivo que cria, de fato, uma visão de mundo centrada em uma postura bem-humorada de se viver. 


\section{NOTAS}

1 Não iremos ressaltar a reivindicação étnica e os conflitos entre grupos locais que foram desenvolvidos em minha dissertação de mestrado. Os grupos que vivem na Gameleira não se consideram descendentes de um mesmo ancestral. Há disputas políticas e recentemente foi ali criada a Associação Quilombola Serra de Gameleira de Baixo.

2 O uso do termo interlocutor remete a um tipo de pesquisa antropológica que preza pelo desenvolvimento de uma relação dialógica na relação pesquisador x pesquisado (Silva 2000).

3 Forró é o mesmo que arrasta-pé, que significa baile reles (bate chinela) ou o mesmo que forrobodó, expressão africana que significa algazarra (Cascudo 1962). A dança se dá entre pares enlaçados. A mulher apoia sua mão esquerda sobre o ombro do parceiro e a mão direita se apoia na mão esquerda do parceiro. Portanto, o casal une as mãos para poder dançar. O homem enlaça a sua parceira pela cintura com a mão direita e a outra mão segura a mão da parceira. As pernas se encaixam em um movimento rítmico embalado pela música motivadora, que também nomeia a festa: o forró.

4 Ressaltando a importância do todo, isto é, à "música na cultura" e à "música enquanto cultura" (Merriam [1964, 1977] apud Pinto 2001)

5 Tal afirmação também coloca em destaque o forte envolvimento das mulheres com as festas, e nos diz muito sobre as relações de gênero construídas na serra.

6 Referência ao conceito formulado por Magnani (1998). 


\section{BIBLIOGRAFIA}

ALBANO, Marilu. 2008. Da cozinha ao terreiro da Mutamba da Caiera (RN). Dissertação de Mestrado, Programa de Pós-Graduação em Antropologia Social - CCHLA. Natal, RN: Universidade Federal do Rio Grande do Norte

AMARAL, Rita de Cássia de Mello Peixoto. 1998. Festa à Brasileira: significados do festejar, no país que "não é sério". Tese de Doutorado. São Paulo, SP: USP.

CASCUDO, Luís da Câmara. 1962. Dicionário do Folclore Brasileiro. Rio de Janeiro: Instituto Nacional do Livro.

CHIANCA, Luciana. 2006. A festa do interior - São João, migração e nostalgia em Natal no século XX. Natal: EdUFRN.

DAMATTA, Roberto. 1981. Carnavais, Malandros e Heróis: para uma sociologia do dilema brasileiro. Rio de Janeiro: Ed. Zahar.

1986. O que faz o brasil, Brasil? Rio de Janeiro: Rocco.

DREYFUS, Dominique. 1996. Vida do Viajante: a saga de Luiz Gonzaga. São Paulo: Ed. 34.

DURKHEIM, Émile. 1978. As formas elementares da vida religiosa. Coleção Os Pensadores. São Paulo: Ed. Abril Cultural.

LANNA, Marcos. 1999. “Festa e Política”. Revista Vivência: Dossiê “A festa” 12(1): 18-30.

LEACH, Edmund R. 1996. Sistemas Políticos da Alta Birmânia: Um estudo da estrutura social kachin. São Paulo: Edusp.

MAGNANI, José Guilherme Cantor. 1998. Festa no Pedaço - cultura popular e lazer na cidade. São Paulo: Hucitec/ Ed. Unesp.

MAUSS, Marcel. 1974. “Ensaio Sobre a Dádiva” In Sociologia e Antropologia. São Paulo: EPU/ EDUSP.

2003. "Ensaio sobre as Variações Sazonais da Sociedade Esquimó". In Sociologia e Antropologia. São Paulo: CosacNaify.

MCCALLUM, Cecília. 1998. "Alteridade e Sociabilidade Kaxinauá: perspectivas de uma antropologia da vida diária". Revista brasileira de Ciências Sociais 12(38).

MÉRIOT, Christian. 1999. “Festas, máscaras e sociedades". Revista Vivência: Dossiê "A festa 12(1): 06-16.

OLIVEIRA, Roberto Cardoso de. 1998. "O trabalho do antropólogo: olhar, ouvir e escrever". In O trabalho do antropólogo. Brasília / São Paulo: Paralelo 15 / UNESP.

PINTO, Tiago de Oliveira. 2001. "Som e música: Questões de uma Antropologia Sonora". Revista de Antropologia 44(1): 221-286.

REZENDE, Claudia Barcellos. 2001. "Os limites da sociabilidade: cariocas e nordestinos na feira de São Cristóvão". Revista Estudos Históricos 28(2). 
SEGALEN, Martine. 2002. Ritos e rituais contemporâneos. Rio de Janeiro: Editora FGV.

SILVA, Vagner Gonçalves da. 2000. O antropólogo e sua magia: trabalho de campo e texto etnográfico nas pesquisas antropológicas sobre as religiões afro-brasileiras. São Paulo: Edusp.

VALERI, Valério. 1979. "Festa". In Enciclopédia VI. Turim: Ed. Einaudi.

VIANNA, Hermano. 1988. O mundo funk carioca. Rio de Janeiro: Jorge Zahar Editores.

WOORTMANN, Ellen. 1995. Herdeiros, parentes e compadres: colonos do sul e sitiantes do Nordeste. São Paulo: Hucitec; Brasília: Edunb. 


\section{Uma serra de forrós: sociabilidade e festas em Gameleiras - RN}

\section{RESUMO}

O presente artigo objetiva compreender como as festas de forró informam sobre a organização social na Serra da Gameleira (RN). Identificam-se os lugares festivos: cinco casas de forró que funcionam com regularidade. Nelas, os espaços públicos e privados apresentam limites tênues entre casa de forró e casa residência. Cada casa de forró tem seu dono que, ao realizar as festas, mobiliza os moradores e favorece o estreitamento das relações sociais. Assim, ao observar a sociabilidade festiva entre os diferentes grupos familiares, que vivem respectivamente em Gameleira de Baixo, Gameleira de Cima e Chaves Belas, o forró aparece como um evento propício à circulação dos indivíduos e aos encontros entre os segmentos sociais no espaço da Serra.

PALAVRAS-CHAVE: festa de forró, Serra da Gameleira, sociabilidade, relações sociais.

\section{A mountain of forrós: sociability and parties in Gameleiras - RN}

\section{ABSTRACT}

This article seeks to understand how the parties of forró dance can inform about the social organization in Serra da Gameleira (RN). We identify the festive places: five houses of forró that function regularly. Inside them, the public and private spaces are intimately related, presenting no clear limits between the house of forró and the residence. Each house of forró has an owner who organizes the parties, mobilizing the inhabitants, and provoking the straightening of social relations. Thus, to observe the festive sociability among different family groups, who live respectively in Gameleira de Baixo, Gameleira de Cima and Chaves Belas, the dance appears as an event conducive to the movement of individuals and to the meetings between the social segments within the Sierra. KEYWORDS: forró, parties, Serra da Gameleira, sociability, social relations. 